Fascists as Much as Painters: Imagination, Overidentification, and Strategies of Intervention

Dr. Stevphen Shukaitis

University of Essex

Address for correspondence

Dr. Stevphen Shukaitis

Lecturer (Assistant Professor)

University of Essex

Essex Business School

Wivenhoe Park

Colchester CO4 3SQ

E-mail: sshuka@essex.ac.uk

March, 2011 


\title{
Fascists as Much as Painters: Imagination, Overidentification, and Strategies of Intervention
}

\begin{abstract}
This paper explores the work of Laibach and the Neue Slowenische Kunst collective from Slovenia, and their usage and fusion of avant-garde and fascist aesthetics as a form of cultural and political intervention into the collective imagination. This approach of adopting a set of ideas, images, or politics and attacking them, not by a direct, open or straightforward critique, but rather through a rabid and obscenely exaggerated adoption of them, is referred to as overidentification. This paper will examine the formation of overidentification as a strategy of cultural-political intervention uniquely suited to this context. Since that period this approach to cultural intervention has been adopted more broadly within political organizing. The argument for such strategies is that in the current functioning of capitalism, the critical function of governance it to be more critical than the critics of governance itself. The question then becomes of how a strategy of overidentification either creates of restrains the possibility of intervening within the creation of collective imaginaries within the present. The ambivalence of overidentification is thus a fitting tool for developing methods of intervention for contexts marked in their very nature by a high degree of ambivalence, and to find ways to recompose a politics in and against these conditions.
\end{abstract}

In 1987, Laibach, the musical wing of the art collective Neue Slowenische Kunst (New Slovenian Art, or NSK), released a reworked version of the Queen song "One Vision." While the Queen song was inspired by their participation in Live Aid and espoused a somewhat vague left liberal message of unity and world peace, it was vastly transformed in Laibach's reworking. While lyrics about there being one race, vision, and solution might easily be passed over as innocuous or not even be taken notice of in the context provided by a performance by Queen (1985), their submerged obscene meaning becomes readily apparent when translated into German and played along in a droning, militaristic style. Laibach's version of the song, far from being a cover or simple copy, through its transformation of the song, draws out and amplifies the grotesque parallels between the pleasures of pop culture and fascist modulation of crowd emotion through propaganda and epic scale theatricality. Why did Laibach do this? Are they fascists or not? If it looks like, talks like, and acts like a fascist (Laibach is famous for always remaining in character), do not be fooled, for it may be a fascist after all. But Laibach's performances (as well as the work of the rest of the projects within the NSK) are premised on undercutting such a clear-cut distinction through their usage of totalitarian aesthetics and bastardization of nationalist themes. They are, and claim to be, fascists as much as Hitler was a painter. Laibach and the NSK operate by adopting the imagery of fascism and state power and pushing it to its limit, recombining it with other elements and traditions, exploring how these connections play out in unexpected and unforeseen ways.

This approach of adopting a set of ideas, images, or politics and attacking them, not by a direct, open or straightforward critique, but rather through a rabid and obscenely exaggerated adoption of them, is referred to as overidentification. While the concept was developed within the theoretical armory of Lacanian psychoanalysis (and later further developed by thinkers such as Slavoj Žižek and various cultural and political activists), it was the NSK Collective that through their work forged it into a tool of cultural subversion and sabotage to be deployed within the ideologically charged context of post-Tito Yugoslavia. This paper will examine the formation of overidentification as a strategy of cultural-political intervention uniquely suited to this context. Is overidentification useful as a strategy of political intervention for a time marked by the presence of cynical distance within the cultural and social sphere, or have the various phases of transition that have occurred since Laibach's founding rendered such methods ineffective? Or perhaps it is possible to refound a critical politics and strategies of intervention drawing from the work of Laibach and the NSK, transforming their methods and ideas to the conditions of the present.

\section{The Explanation is the Whip and You Bleed}

$$
\text { - "Apologia Laibach" (1987) }
$$


Laibach is a Slovenian avant-garde musical performance group that was founded in 1980. They were one of the founding members of Neue Slowenische Kunst (NSK) in 1984, along with IRWIN (painting) and Scipion Nasice Sisters Theater (who subsequently changed their name to Noordung). Although this essay will discuss focus primarily on Laibach's work, motifs, ideas, and images are frequently shared, developed, and elaborated by the various branches of the NSK, whether independently or as part of joint ventures. Since its inception the NSK has expanded to include other activities including philosophy, planning, architecture, and many other aspects that are part of its now proclaimed status as a 'global state in time.' In addition to the collective development of shared themes, the various collectives composing NSK emphasize the collective nature of the project, not crediting individual members for aspects of the work and frequently changing the composition of the members involved in any given production. As a musical project, Laibach is mainly associated with forms of industrial music (as well as neoclassical and martial styles), evolving during the career from a very harsh and abrasive sound during the early recordings through to one at times involving multiple layers of electronics, heavy metal, compositions arranged in the form of national anthems, and most recently interpreting a series of Bach's fugues. But Laibach, and the NSK more generally, have achieved prominence, notoriety, and infamy perhaps less so for their particular aesthetics as much as the historical meanings and recontextualizations of the various elements used in their performances and productions. The name "Laibach" itself, for instance, has been the German name for Ljubljana for ages, but its more recent historical association is its imposition during the fascist occupation.

The work of Laibach and the NSK frequently draws upon the aesthetics of totalitarian and nationalist movements, forging a kind of totalitarian kitsch by fusing together elements from varying and completely incongruent political philosophies. For instance the NSK logo itself is a combination of Laibach's cross logo (borrowed from Russian supremacist artist Kasimir Malevich; it was used as its primary public reference point during the years when the name Laibach was banned in Yugoslavia), John Heartfield's anti-fascist axe swastika, an industrial cog and a pair antlers (with the base of the design featuring the names of the founding collectives).

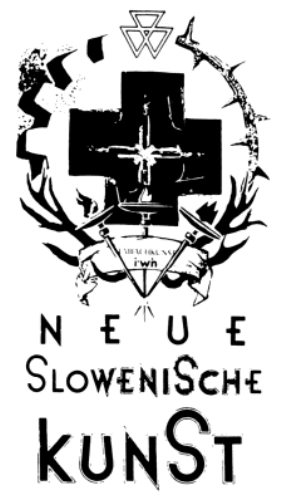

Even in this small example one can see an ambiguous and strange merging of elements, the way that the anti-fascist emblem becomes ambiguous and transformed within a composition where the relation of the elements to each other changes the meaning contained within each of them. Laibach and the NSK do not employ such elements in gestures of repetition, but rather treat them as ideological and aesthetics readymades (in the Duchamp-ian sense) whose combination creates ambiguous and disconcerting effects.

Laibach / NSK's usage of historical and political readymades and images in their work obscures and conceals as much about their origin as it reveals. In this way they render audible amplify their submerged and hidden codes and desires, or what Žižek refers to as the hidden underside of systems and regimes. This approach to the use of borrowed historical and political elements forms the basis of what Laibach/NSK refer to as retrogardism, or the formation of the 


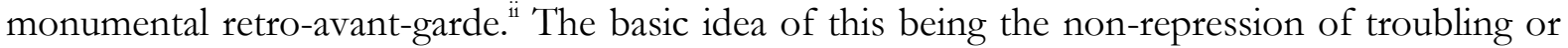
undesirable elements of historical and social regimes in their work. Rather than repressing them they are highlighted, as they argue that the traumas affecting the present and the future can only be addressed by tracing them back to and through their sources, work through and processing them. As Alexei Monroe argues in his analysis of their work, it is not an approach based on constructing a new future by negating the past (which in general is the usual relation to time found within avant-garde artistic practice), but rather "retrogardism attempts to free the present and change the future via the reworking of past utopianisms and historical wounds" (2005: 120). Rather the impact and effect of Laibach/NSK's work is based on the effects produced by the disjunctive synthesis of troubling historical elements and the radical ambivalence contained within them when re-contextualized.

As has been argued by Žižek ${ }^{\text {iii }}$ and others, in actually existing socialist democracy sustained by a set of implicit (obscene) injunctions and prohibitions. Thus there is a necessary process of socializing people into the practice of not taking certain explicitly expressed norms. Tactics of overidentification, as employed by Laibach and the NSK (as well as more broadly within the Slovenia punk subculture of the 1980s that gave birth to the genre of "state rock," or punk music incorporating elements as the discourse of self-managed socialism as critique through overidentification), work precisely by taking the stated norms of a given system or arrangement or power more seriously than the system that proclaims them itself. ${ }^{\text {iv }}$ This operation occurs not through addressing the law itself, per se, or by breaking prohibitions (a more straightforward form of transgression), but rather teasing out the obscene subtext that underpins the operation of the law and supporting social norms. A strategy of overidentification, in order to be effective to appear total, and through that it "transcends and reactivates the terror of the social field... the spectral menace of totality gives the phenomenon sufficient 'credibility' to sow doubt and disquiet" (Monroe, 2005:79). And this is precisely how Laibach/NSK work functions, through giving an impression of totality (by claiming the status of the nation, or the state, or of being a global state in itself) in a manner that lends a degree of credibility to the menacing and disconcerting nature of their aesthetic production.

As Susan Buck-Morss (2002) explores in her work on transitions within collective imaginaries and the fading away of mass utopian visions, dreamworlds become dangerous when they are used instrumentally by structures of power, which is to say as legitimation devices and discourses. But these rhetorical structures of legitimation vary in how they are translated into dimensions that dominate the visual field. Broadly speaking Buck-Morss breaks down into strategies connected to nation states, which she argues are formed around a primacy of space in their imaginal functioning, and the rhetoric of class war, which she argues are formed around notions of time and history. As she claims, protagonists in class struggle are not spatially delineated: "the terrain of class war, as civil war, is spatial confusion" (2002: 24). If this were to be true that would place avant-garde movements working in alliance within movements of class struggle in an especially strange place should these movements actually succeed and move from a status of constituent to constituted power, in other words from class struggle to state making. In Buck-Morss' framing this would entail a change in the structure of rhetoric and visual legimitation, and is perhaps part of one reason (among many) that early avant-garde movements found themselves in quite precarious place: forced to choose between keeping to their core principles and often traumatized by the comprises involved working within the conditions of state legimitation in a post-revolutionary situation.

Buck-Morss argues that socialism failed because it mimicked capitalism too faithfully. Conversely one could argue that avant-garde artistic movements failed when they were caught in these changing conditions of legitimation. It is when, as Boris Groys suggests (1992), the project of sublating art into everyday life, which is to say preserving it while negating it as a separate and autonomous domain or area (the idea of 'art for art's sake'), was transformed. For Groys this is the move from the avant-garde idea of art as everyday practice into something else: a "total art of 
Stalinism." In other words where the avant-garde desire for the reshaping of the totality of everyday life as an art form was perversely realized as the drastic reshaping of life in a truly most dramatic fashion by the Stalinist state. Laibach and the NSK work by turning this process of mimicry against itself, disarticulating the potency of the dreamworld and utopian promise of communism that had become embedded within a discourse of legitimation and mixed with the lingering presence of totalitarian and authoritarian elements. They also work to excavate the trauma experience of the avant-garde during this transition within legimitation strategies of the structures of artistic expression within state structures. Indeed, it is often that the constituted forms of power existing with state structures are based upon the ability to draw from the energies and constituent power of social movement, of utopian dreamworlds, and render them into zombified forms of state legitimation (Shukaitis, 2007). NSK / Laibach's interventions were so powerful within the Yugoslav context precisely because of how they amplified and made visible this process of rendering dreamworlds into discourses of state legitimation, from the mythified versions of Slovene history to the continuing use of partisan imagery and themes. These interventions provide through their disconcerting effects ways to work through both the continued presence of authoritarianism and utopian energies, as well and how they are completely enmeshed and intertwined in the workings of existing social imaginaries and political discourses.

Laibach's work incorporates a good deal of official Yugoslav discourse on selfmanagement and social democracy, using at times sections of Tito's speeches and audio recordings, as well as particularly resonant forms of Slovene history. It is this reworking of Slovenian and Yugoslav history that invested their early works with such potency, through the way these familiar ideas were made strange and even incomprehensible to audiences through their fusing and juxtaposition with other elements (for instance by fusing them together with Germanic imagery and phrasing, which was anathema to nationalist groups). Laibach's response to this, particularly in relation to the continued controversy over its use of the a name which was said to dishonor the 'hero city' of Ljubljana, was to continue to adopt a stance of complete identification with Slovenia and Slovene identity, and thus to frame controversy and rejection of Laibach as the rejection of Slovenia itself. This creates a form of ambivalent identification in which Laibach both bastardizes (in their critics views) Slovene identity while at the same time engaging in a quite militant assertion of that very Slovene identity (at points even declaring the German to be a subset of the Slovene). Through the politics and practices of overidentification Laibach and the NSK hint towards the possibility of breaking the very process of identification, ${ }^{v}$ and this is why they were so disconcerting for many political actors in Slovenia in the 1980s.

Laibach / NSK's politics and practices of overidentification are displayed in unique and quite fascinating ways in their organizational practices, or at least that claims they make about their organizational practices. This shows through in their claimed structure, which is shown by the NSK organigram from 1986, which takes the logic of alternative forms of institutionalization to an almost absurd extreme. 


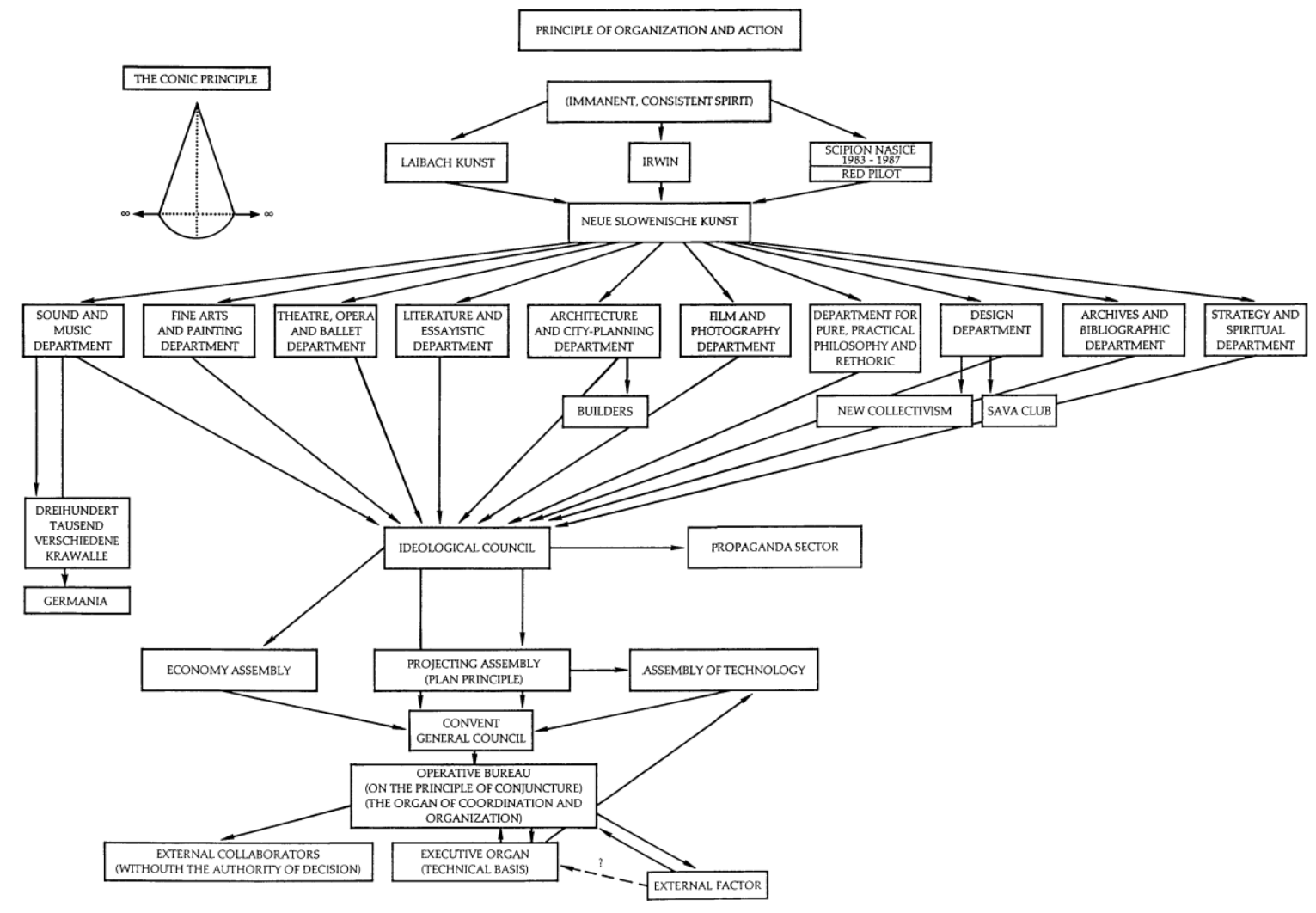

In the organigram at least ten different departments in addition to a number of assemblies, councils, and organs, all paired with or ruled over by the statement of 'immanent consistent spirit' that covers and directs all the activity of NSK. This claiming of and overidentification of overly complex, arcane, and nearly incomprehensible state-like structures was observed by the Rough Guide to Yugoslavia to bear a striking resemblance to the diagrams used within school textbooks to explains the country's bafflingly complex political system and structures (Dunford et al, 1990: 244). It is through this that the spectral menace of totality is activated, for in the case of the NSK it clearly is spectral because the NSK is composed of many more organizational components than it has ever possessed as members. This becomes more so during the case in projects such as the "State in Time," in which the claiming of a state structure existing purely in time is enacted through overidentification with the organizational form and structure of states. In all of Laibach and the NSK's work there is never a clear cut statement on organization but rather an exploration of its ambivalences and possibilities; this is an approach that "does not support a utopian or dystopian organization, but the fantasies of audiences that need to imagine that such possibilities still exist" (Monroe, 2005: 113).

The first phase of Laibach's work is based around the usage and working through of elements and histories that are particularly resonant and provocative within a Yugoslav, and specifically Slovenian context, but often have little to no meaning outside of it. This perhaps comes to its highest point of concentration in the 1986 NSK joint production Krst pod Triglavom (Baptism Under Triglav), which was a monumental drama roughly based around the history of the forced Christianization of the Slovenes, interspersed in NSK fashion within many other layers of history and processed through the imagery of the avant-garde (for instance the recreation of Vladimir Tatlin's proposed monument to the Third International as part of the set design). This production, which took place in a large state sponsored theater, is interesting not just in the merits of its internal aesthetics, but also in how it illustrates that changing status of Laibach and the NSK within social context (particularly given the greater importance of state backing and commissions within socialist systems). That is to say that it makes the transition of Laibach/NSK's work from its emergence within alternative and subcultural milieus to an 
acceptance, even if tentative and grudging, by state authorities. It marks what Monroe refers to as the Laibachization of Ljubljana (2005: 155), or the process of confronting and reworking cultural boundaries and norms that occurred during the 1980s, from the point of the banning of Laibach appearing under its chosen name through to their international success through which Laibach's fanatical identification with Slovenia came to be realized through their being recognized as the most successful Slovenian artists.

Laibach's rise to prominence in the mass media, especially internationally, occurred at a point where in time where attempts where being made to shift the image of Yugoslavia closer to one of a western humanist democracy. Laibach presentation of itself in terms of a cold neototalitarian front functioned both to invoke forms of authoritarian legacies and images that the Yugoslav government wanted to reject while at the same time while at the same time becoming the most prominent and aggressive assertion of Yugoslav (and particularly Slovene) culture on a global stage (although the fusion of Germanic elements and imagery within Laibach's imagery meant that they were often taken to be German by casual music fans, even more so during the 1990s with the rising popularity of German industrial bands). Laibach's success showed that it was "actively connected to the zeitgeist, but specifically to those subterranean, unforeseen elements repressed by mainstream consciousness" (Monroe, 2005: 75), specifically the lingering presence of authoritarian, fascistic elements, totalitarian, militarism, in the self-management system itself

This period marks a transition within Laibach's work. It is a shift from an early phase oriented around interventions drawing heavily upon local histories and references to one more oriented to broader audiences formed global cultural flows and media environments. It is this logic that underlies Laibach's reinterpretation of the Queen song that began this essay as well as all the other covers and reinterpretations that Laibach have engaged in. In their reinterpretation and reworking of the Queen song, Laibach are not attributing any particular political agenda to Queen per se, but rather are engaged in a process of amplifying the ambivalences that are already contained within Queen's performance. It is not that Laibach brings a fascist aesthetic to bear on a Queen song, but rather there is a similarity and underlying dynamic between totalitarian mass mobilization and capitalist mass consumption. Laibach's work is premised upon amplifying and bringing out this underlying ambivalence and tension, and to present this strangeness back to an audience as a reflection and fracturing of the structures and imaginaries through that crowd has been constructed and constructs itself. While the reinterpretation of the Queen song is the most striking, there is a similar process and logic that underlies other reinterpretations, such as their versions of the work of the Beatles (1989), Europe (1994), Opus (1987). More recently Laibach, extending the global state in time project, have taken to reinterpreting the form of the national anthem itself (2006).

This contrasts sharply with the forms of artistic production that Charity Scribner (2003) describes in her book Requiem for Communism. The examples that Scribner explores, from Krzysztof Kieślowski to Rachel Whiteread's empty space and resin sculptures, seem affected by an almost involuntary melancholy or mourning. For Scribner they capture accurately an affective state where the perceived failure of creating a workers state or welfare state is mourned, but not necessarily in a way where that mourning leads to the idea that they can be repaired, rebuilt, or even anything done about the situation. In this sense there is still a lingering attachment, but with without any of the potential remaining. Scribner documents artistic forms where lingering attachments persist to a symbolic universe that has lost its potency to reshape forms of collective imagination that could reshape the world: they are barren. The work of the NSK and Laibach is almost exactly the opposite of this in how it engages with existing symbolic sets. Far from holding on to an aesthetics without potential in their work there only seems to be attachment to previous sets of symbols and ideas precisely because of their lingering transformative, albeit ambivalent, potential. The idea of the retro-avant-garde is based precisely around the task of re- 
activating the residual potency residing in ideologies and aesthetics long thought (or even wished) to be dead.

Laibach's reworking and transformation of other artists materials render them into totally different compositions in terms of their feel and nature through relatively minor changes in tone, orchestration, and lyrics. This approach is quite along the lines of what Deleuze and Guattari discuss as the formation a minor literature (1986), one based not on the development of a new representative form of language but rather working within the existing major languages and turning them against themselves to create strange new forms. Laibach and the NSK's artistic productions, as they take part and intervene in the Yugoslav and regional social political context (and beyond that), create the basis for the formation of what could be described as a minor politics (Thoburn, 2003) and the minor composition of social movement (Shukaitis, 2008). It is a minor movement in the sense of not trying to create a new language and form of its own, but rather to hollow out a space where meanings are transformed within the dominant languages and social norms. Laibach's reworking and fusing together of widely differing pre-give aesthetic and ideological elements, sources they treat as readymades be to transformed through recombination, can be understood as a particular form of what the Situtaionist International referred to as détournement. Détournement, or literally translated 'embezzling,' involves the combination of pre-existing aesthetic elements and ideas. But while détournement has often bee understood in a rather watered down way in terms of forms of culture jamming based on witty recombination and mixing of elements that work based on a fairly easily recuperable form of critique (for instance Adbusters), the work of Laibach and the NSK is much harder to make palatable. Most détournement based culture jamming relies upon maintaining a kind of critical distance from the elements used, while Laibach's work functions through a total and fanatical identification with obscene subtext of the elements they employ. In this sense Laibach return to a much deeper sense of détournement as the fundamental questions of worth and communicability in any system of meaning, and from this developing tactics for monkey wrenching in the fundamental structures of the production of meaning. Laibach's recombination of ideas, images, and politics does not simply recombine them, but act to transform the potential of the elements used to create meaning in relation to each other, and through that acts as form of semiotic sabotage in the public sphere, at times critically damaging the ability of these symbols to operate.

\section{Strategies of Overidentification}

"He who has material power, has spiritual power, and all art is subject to political manipulation, except that which speaks the language of this same manipulation." - Laibach, 1982 (quoted in Djuric, 2003: 574)

But let us step aside from Laibach and the NSK's particular cultural and political interventions to consider the role and practice of overidentification in a broader scope. Overidentification as a practice of political intervention could indeed function as the unifying nodal point of a Lacanian left (Stavrakakis, 2007/2008), if indeed such a thing actually existed (Cederström, 2007). ${ }^{\text {vi }}$ Since that period of Laibach's rise to international attention in the late 1980s, this approach to cultural intervention has been adopted more broadly within political organizing, and can be identified in the activities of groups such as the Yes Men, Michael Moore, Christoph Schlingensief, Reverend Billy, the Billionaires for Bush, and many others. The argument for such strategies is that in the current functioning of capitalism the critical function of governance is to be more critical than the critics of governance. Functionaries in a system of power, by presenting themselves as their worst critic, thus deprive critique of its ammunition and substance, thereby turning the tables on it. This is to beyond both the arguments put forward by Boltanski and Chiapello that critique has been subsumed within capitalism (2005) and within the autonomist politics that forms of social resistance and insurgency are the driving motor of capitalist development (rather than being reactive to it). This hints at the possibility that 
strategies for the neutralization of the energies of social insurgency are anticipated even before they emerge, or what Mark Fisher (2009) describes as "precorporation" (rather than recuperation). It is in this context that a strategy of overidentification is argued to be of particular value, throwing a wrench in the expected binaries of opposition and response.

The most worked out conceptualization of overidentification as a strategy of intervention was developed by BAVO, which is an independent research project focused on the political dimensions of art and architecture, primarily based on co-operation between Gideon Boie and Matthias Pauwels. ${ }^{\text {vii }}$ Based in Rotterdam, BAVO's initial efforts responded to attempts to apply to culture-based regeneration, such as has been employed in the continued reshaping of Amsterdam as creative and bohemian, yet ultimately gentrified, location (2007b). It is this particular role reserved for artists in a cultural led regeneration process, as being both central to it yet unable to do anything but voice an ultimately pointless form of dissent, that leads BAVO to reconsider what might be different strategy of artistic-political intervention. Overidentification for BAVO becomes another way to reformulate dissent when previous forms of cultural-artistic intervention have become integral to the very social processes they are ostensible objecting to in the first place.

Although their takes on these matters is far ranging as can be seen by the varied contributions and examples they gathered together for their edited collection Cultural Activism Today. BAVO uses the concept of overidentification to draw together and theorize forms of cultural intervention that would easily appear to have no connection to each other at face value, such as Reverend Billy's anti-consumerist Baptist preacher antics with Christoph Schlingensief's staging of an event where asylum seekers are voted out of Austria in a Big Brother-style reality television program. Despite the variety in forms these interventions take within there is an underlying similarity of approach. From this BAVO draw out a few key points illustrating their perspective.

BAVO suggests that we are living in post-political times where it is possible for artists and political actors to say anything, but what is said does not matter. This describes the way that artists are integral to economic and social interactions, as creators of value and new ideas, but nevertheless totally disempowered when they take on any role other than that. However a certain degree of critically in held as necessary and desirable. Today, it is argued, artists are expected, and even demanded to play something of a critical function, as long as one does not go too far in that function, in other words to question the fundamental ideological coordinates underpinning social relations, as by doing so "one is immediately disqualified as a legitimate discussion partner, treated like an incompetent, ignorant imbecile who stepped out of line and should better stick to his own field of experience" (2007: 19). From this they argue, following Karl Kraus, that when forced between two evils, one should take the worst option. That is, to abandon the role of pragmatic idealists and to work to force an arrangement of contradictions to their logical end. In their words

Instead of fleeing from the suffocating closure of the system, one is now incited to fully immerse oneself in it, even contributing to the closure. To choose the worst option, in other words, means no longer trying to make the best of the current order, but precisely to make the worst of it, to turn it into the worst possible version of itself. It would thus entail a refusal of the current blackmail in which artists are offered all kinds of opportunities to make a difference, on the condition that they give up on their desire for radical change (2007a: 28)

One can certainly argue, and there has been much argument, about the nature and details of this proposal. BAVO adopts such an approach as they argue that other possible strategies, such as those as working on the grounds of marginal positions or creating forms of exodus, have already been anticipated and accommodated by systems of capitalist governance, and therefore no longer are useful as disruptive strategies (2007a: 29). It is within this context that the work of 
group such as the Yes Men becomes more interesting, precisely because rather than putting forth forms of critique that can easily be brushed aside, their tactics of fanatically identifying with the neoliberal agenda, thus pushing them further along to obscene but logical developments of such ideologies. This is the same stance the Laibach and the NSK employ, one based not on critical distance, but rather erasure of such distance. And it is through this erasure of distance that the Yes Men's opponents are thrown off guard, precisely because, as BAVO describe it, this form of intervention forces them to betray their articles of faith and passionate attachment to a neoliberal agenda as the obscene subtext is made clear, and thus forces "makes it [the WTO] - rather than its critics - appear weak" (2007: 30). ${ }^{\text {viii }}$

A strategy of overidentification thus provides one possible antidote to what Peter Sloterdijk (1998) refers to as cynical reason, or a condition where people know that there is something fundamentally wrong but continue to act is this is not the case. It is this cynical distance that Jeffrey Goldfarb diagnosed as so prevalent in the US (1991), creating a sort of "legitimation through disbelief," although one could easily argue that this is much more widespread and just the condition that a strategy of overidentification aims to address and intervene within. One can certainly contest the desirability and effectiveness of such an approach, and such strategies have and continue to create a great deal of debate within political, artistic, and academic circles. Nevertheless, even if the conclusion is eventually reached that such is not an acceptable choice of interventionist strategy in most cases, it nonetheless seems valuable to learn from especially in making a transition out of a time frame or frame of mind that is paralyzed to find any method of intervention because all strategies are already caught in varying webs of power and therefore argued to be compromised. A strategy of overidentification operates precisely by turning this already-caught-ness into an advantage by deploying and redirecting energies of capture and constituted power against themselves.

Žižek, in an essay on Laibach and the NSK, comments that the reactions of the left to them has first been to take their work as a ironic satire of totalitarian rituals, then followed by an uneasy feeling based on knowing whether they really mean it or not. This is usually followed by varying iterations along these lines, wondering if they really do mean it, or whether they overestimate the public's ability to interpret their multiple layers of allusion and reference and thus end up reinforcing totalitarian currents. For Žižek these are the wrong questions to ask and angle to take. Rather, it is a question of how Laibach and the NSK, as well a strategy of overidentification more broadly, intervene in a social context marked by cynical distance. From this perspective he asks

What if this distance, far from posing any threat to the system, designates the supreme form of conformism, since the normal function of the system requires cynical distance? In this sense the strategy of Laibach appears in a new light: it 'frustrates' the system (the ruling ideology) precisely insofar as it is not its ironic imitation, but overidentification with it - by bringing to light the obscene superego underside of the system, overidentification suspends its efficiency (1993).

What could this mean for the politics of artistic intervention that projects such as Laibach and the NSK are working within? To approach it from another angle, Jacques Ranciere has made the argument that the history of relations between political and aesthetic movements is one of a confusion between two ideas of the avant-garde embodying competing conceptions of political subjectivity. Thus for Ranciere the very idea of a political avant-garde is "divided between the strategic conception and the aesthetic conception" (2004: 30), which has consequences in how the attempt by artistic-political interventions to reshape the distribution of the sensible (to use Ranciere's phrasing) plays itself out. One could argue that the history of avant-garde movements is precisely based on trying to erase the boundaries between an aesthetic and a strategic approach to politics, for example in the way that the Situationists formed a political praxis around creative 
interventions and aesthetic disruption in the fabric of everyday life. The avant-garde has tended to operate through a declaration of the new, of an announcement new distribution of the sensible (which is often taken for granted to have occurred with the initial manifestation of the movement in question), and through the operation of new forms of social and political praxis.

The work of the Laibach and the NSK, as well as others working with a strategy of overidentification, takes a different approach. The efficiency of this obscene submerged power that Žižek identifies works precisely because it is formed around something that everyone knows but that no one can say they know, at least openly. It is the shared secret that cannot be openly expressed and creates commonality through its lack of open acknowledgment. This is very much the role for aesthetics that Ranciere describes, somewhat paradoxically as "the police," which functions in the administration of what is said and what can be said. As a strategy of politicalaesthetic intervention, overidentification does not simply declare the content of the submerged obscene forms of power, to act to reveal them as straightforward critique. This would not be effective in such a situation precisely because the conditions are already known by those involved. Overidentification operates then through taking the claims embedded in the situations more seriously then taken by the system of power administering them takes itself, and pushing that to its limit, and if possible beyond it.

The question remains, however, to what degree a strategy of overidentification is marked by the conditions that led to its emergence. If overidentification was effective in its ability to disrupt circuits of meaning and the social imaginary within a particular social and historical context, it does not necessarily follow that it will operate similarly in other, possibly significantly different situations. Might then a transition within the imaginary of a politics formed around aesthetic interventions premised upon overidentification be necessary? This is perhaps what one sees in the development of Laibach's work, which moves from operating as a disruptive mechanism in and against the Yugoslavian national imaginary during the 1980s, but then changes direction following the disintegration of the country. For instance, during the 1990s the NSK launches it "State in Time" project, where it claims to have created a global state and system of governance that is not based in physical space but only in time. This is at the same time a movement away from a strategy of disruption of one imaginary towards a new form of imaginary disarticulation, and can in some ways be seen more to be based on a nostalgic identification with the state form that been torn apart than an act of overidentification. In other words it had become possible for Laibach and the NSK to transition away from disarticulating the Yugoslav imaginary through overidentification and to begin a more positive assessment of the state dynamics it had fused itself too. This is perhaps not so surprising when one takes into account Sharon Zukin's argument that it is only really possible to fully aestheticize a system or relations of production one it has passed its moment as the hegemonic form of production (1989).

It is to return to the questions of what a strategy of overidentification is ultimately based on, what does it accomplish, and to what end. While it tempting to brush off questions of the difference between parody, satire, and overidentifiction, this would be a mistake because it is precisely in these differences that overidentifiction as strategy achieves it unique function. This conflation of overidentification and related concepts would be especially tempting precisely of how humor and satire have been taken up in the US by the left as a response to the politics of fear-mongering, for instance in the increased prominence of Jon Stewart and The Daily Show, Stephen Colbert and The Colbert Report, and the satirical newspaper The Onion (Day 2011). Colbert serves as an example of how these related phenomena seem to overlap through the way that he adopts the style and composure of a right wing news anchor to undermine the political right through parody and imitation. But what makes what Stephen Colbert and Jon Stewart is doing different from overidentification is that it is never left unclear what their position is on the role they are adopting to make their point. Viewers are unlikely to think that what is being said is serious, which is much different from the activities of Laibach and the NSK where ultimately their position is left open and is thus unsettling. Overidentification as a strategy operates through 
avoiding this closure, even if it is a closure that would be reassuring rather than leaving the audience unsettled.

To frame this difference in terms that owe more to a Deleuzian approach to aesthetics, one could say that overidentification is based upon engaging the virtual within the actual rather than assuming or trying to create a position on the outside where critique can operate from. Conversely parody and satire function by assuming that there is place that is not complicit with the forms of power engaged. Parody and satire thus work by expanding or enlarging this social distance as a basis for critique, often times to quite useful effect (Kenny 2009), while overidentification works precisely by collapsing the distance as much as possible, by rejecting the idea that there is position of non-complicity to engage with fields of power. This is to work, for instance, by teasing out the anti-nationalism contained within nationalism (which Laibach do in their recent Volk album), or the underlying fascist crowd dynamics within the pop anthem (as Laibach did in much of the their material in the 1980s). In this difference, based on not being able to assume a distance from power, that Laibach, and a strategies of overidentifiction, open new conditions for critique and intervention within the social precisely through their apparent collapse.

The question of transition and intervention within the social imaginary is transformed if one works an argument such as the one made by Guy Debord (1998), that rather than there existing a sharp and total distinction between Western capitalism and Eastern communism, it was rather a question of the difference between the workings of a diffuse and concentrated spectacle. In other words, not of totally different forms, but rather of particular compositions of a similar underlying dynamic of power and exploitation. Any attempt to shape a new form of social imaginary for revolutionary politics that takes as a given this demarcation would be bound to fail precisely because it has misapprehended the configuration of political, economic, and social forces that it is operating within. From this perspective overidentification as a strategy takes on its value precisely because it does not assume any clear difference between configurations of power, and does not try to operate by claiming a space outside of the present in which it finds itself.

The question then becomes of how a strategy of overidentification either creates of restrains the possibility of intervening within the creation of collective imaginaries within the present. One can perhaps stumble towards the position that overidentification provides another wrench in the conceptual toolbox for refounding and reformulating critique. It provides a possible answer to the dynamics analyzed by Peter Starr in his exploration of the dynamics of failed revolt in post-68 political thought (1995). Starr argues that modern revolutionary thought is premised upon radical breaks and departures from the past, one that suppresses previous notions of return and reappearance of social forms. And it is this dynamic of reappearance that gives way to a fanatical obsessions with dynamics of recuperation, as they run counter to the narrative structure of revolutionary politics. Starr argues that the ultimate direction laid out in post-68 thought moves toward a notion of impossible and total revolution, and thus failing there moves towards forms of cultural politics based on subtle subversion. A strategy of overidentification, as well the of the retro-avant-garde and working through the remaining utopian energies and traumas of the past, opens up other avenues for reformulating critique and intervention based upon working from problematic dynamics and elements to be worked through rather than repressed (Goddard 2006). A strategy of overidentification enacts a transition away from considering the dynamics recuperation as problems to be avoided to considering them as possibilities to be exploited and worked through, in, and against, but only against by working in them rather than seeking escape through them by recourse to an unproblematic outside.

The applicability of overidentification is not founded upon its straightforward and unproblematic nature, but precisely because of its very ambivalence. Overidentification becomes a way not to provide a completely worked out solution or direction to the problems posed by the 
current political situation, but rather works to refuse the closure enacted by the existence of roles and positions through which dissent is accepted and desired even if it is ultimately powerless to affect any significant change. To the degree that capitalism and the state (whether in liberal democratic, bureaucratic collective, or any number of other possible forms), derives its continued existence by drawing from the energies and creativity of social resistance, one can say that this dynamic is ambivalent for all sides involved. And if we really are living in an "age of fantasy," as Stephen Duncombe argues (2007), overidentification is thus a fitting tool for developing methods of intervention for contexts marked in their very nature by a high degree of ambivalence, and to find ways to recompose a politics in and against these conditions. Overidentification becomes one way to work through and against the problem that the autonomist hypothesis (resistance to capital provides capital with its future) poses: by refusing the pre-given role of an accepted but subordinated politics of resistance. Overnidentification responds to the problem of "precorporation" where culture pre-emptively formats and shapes desires according to its logics of accumulation, but demands that the appearance of resistance to continue. In such a situation overidentification abandons the role of the loyal resistance for pushing the internal contradictions of power to their limit, making the best out of choosing the worst option. While this frustrates desires for easily known, clearly marked boundaries, the conditions addressed are those that comprise politics today: a hyper-mediated, networked sociality where the overwhelming flows of information, ideas, and immaterial labor threaten to resurrect desires for stability and the imagined security provided by forms of archaic social attachments and identification, whether in the form of renewed nationalisms, religious fundamentalism, or paranoid reactionary forms of identity politics (Berardi 2009; Dean 2009). Overidentification is a strategy for rearticulating the imagination of a radical politics, not through a form of critique attempts to stand outside the present, but rather than operates through pushing forward the contradictions and intensities found with the mutating networks of collective imagination in the present.

\section{References}

Arnaud, G. (2002) "The organization and the symbolic: organizational dynamics viewed from a Lacanian perspective," Human Relations 55(6):691-716

Arnaud, G. (2003) "A coach or a couch? A Lacanian perspective on executive coaching and consulting," 56(9): 1131-1154.

Badovinac, Zdenka, Ed. (1999) Body and the East: From the 1960s to Present. Cambridge: MIT University Press.

BAVO, Gideon Boie, Matthias Pauwels. Eds. (2007a) Cultural Activism Today. The Art of OverIdentification. Rotterdam: Episode Publishers.

BAVO, Gideon Boie, Matthias Pauwels. Eds. (2007b) Urban Politics Now: Re-imagining democracy in the neoliberal city. Amsterdam: NAi Publishers.

Berardi, F. (2009) Precarious Rhapsody: Semiocapitalism and the Pathologies of the Post-Alpha Generation. New York: Autonomedia.

Boltanski, Luc and Eve Chiapello (2005) The New Spirit of Capitalism. Trans. Gregory Elliot. London: Verso.

Buck-Morss, S. (2002) Dreamworld and Catastrophe: The Passing of Mass Utopia in East and West. Cambridge: MIT Press.

Cederström, C. (2007) "The Lacanian Left Does Not Exist," ephemera: theory \& politics in organization 7(4): 609-614.

Contu, A. (2008) "Decaf Resistance: On Misbehavior, Cynicism, and Desire in Liberal Workplaces," Management Communication Quarterly Volume 21 Number 3: 364-379. 
Day, A. (2011) Satire and Dissent: Interventions in Contemporary Political Debate. Bloomington: Indiana University Press.

De Cock, C. and Böhm, S. (2005) "Everything you wanted to know about organization theory... but were afraid to ask Slavoj Žižek," The Sociological Review 53: 279-291.

De Cock, C. and Böhm, S. (2007) "Liberalist Fantasies: Žižek and the Impossibility of the Open Society," Organization Volume 14 Number 6: 815-836.

Dean, J. (2009) Democracy and Other Neoliberal Fantasies: Communicative Capitalism and Left Politics. Durham: Duke University Press.

Debord, G. (1998) Comments on the Society of the Spectacle. London: Verso.

Deleuze, Gilles and Félix Guattari (1986) Kafka: Towards a Minor Literature. Trans. Dana Polen. Minneapolis: University of Minnesota Press.

Djuric, D. and M. Suvakovic, Eds. (2003) Impossible Histories: Historical Avant-gardes, Neo-avantgardes, and Post-avant-gardes in Yugoslavia, 1918 - 1991. Cambridge: MIT University Press.

Duncombe, S. (2007) Dream: Re-Imagining Progressive Politics in an Age of Fantasy. New York: New Press.

Dunford, M., et al, Eds. (1990) Yugoslavia: The Rough Guide. London: Harrap Columbus.

Fisher, M. (2009) Capitalist Realism. Is There No Alternative? Winchester: Zero Books.

Fleming, P. and A. Spicer (2007) Contesting the Corporation: Struggle, Power and Resistance in Organizations. Cambridge: Cambridge University Press.

Goddard, M. (2006) "We Are Time: Laibach/NSK, Retro-Avantgardism and Machinic

Repetition," Angelaki: A Journal of the Theoretical Humanities 11(1): 45-54.

Goldfarb, J. (1991) The Cynical Society: The Culture of Politics and the Politics of Culture in American Life. Chicago: University of Chicago Press.

Groys, B. (1992) The Total Art of Stalinism: Avant-Garde, Aesthetic Dictatorship, and Beyond. Princeton: Princeton University Press.

Monroe, A. (2005) Interrogation Machine: Laibach and the NSK. Cambridge: MIT Press.

Harney, S. and N.Q. Nyathi (2007) "Disidentity," Exploring Identity: Concepts and Methods. Ed. Alison Pullen, Nic Beach, and David Sims. London: Palgrave: 185-197.

Hewitt, A. (1993) Fascist Modernism: Aesthetics, Politics, and the Avant-Garde. Stanford: Stanford University Press.

IRWIN, Eds. (2006) East Art Map: Contemporary Art and Eastern Europe. Cambridge: MIT University Press.

Kenny, Kate (2009) “'The performative surprise': parody, documentary and critique," Culture and Organization Volume 15 Issue 2: 221-235.

Laibach (1987) Slovenska Akropola. Ljubljana: ŠKUC Ropot.

Laibach (1987) Opus Dei. London: Mute Records.

Laibach (1994) NATO. London: Mute Records.

Laibach (2006) Volk. London: Mute Records.

Pullen, A. and S. Linstead, Eds. (2005) Organization and Identity. London: Routledge.

Ranciere, J. (2004) The politics of aesthetics: the distribution of the sensible. London: Continuum.

Reynolds, S. (2005) Rip It Up and Start Again. Post-punk 1978-1984. London: Faber and Faber.

Roberts, J. (2005) “The Power of the 'Imaginary' in Disciplinary Processes," Organization Volume 12 Number 6: 619-642.

Scribner, C. (2003) Requiem for Communism. Cambridge: MIT Press.

Shukaitis, S. (2007) "Plan 9 from the Capitalist Workplace: Insurgency, Originary Accumulation, Rupture" Situations: A Project of the Radical Imagination Volume 2 Number 2: 95-116.

Shukaitis, S. (2008) "Dancing Amidst the Flames: Imagination and Self-Organization in a Minor Key" Organization Volume 15 Number 5: 743-764.

Sloterdijk, P. (1998) Critique of Cynical Reason. Minneapolis: University of Minnesota Press.

Starr, P. (1995) Logics of Failed Revolt: French Theory After May '68. Stanford: Stanford University Press. 
Stavrakakis, Y. (2007) The Lacanian Left: Psychoanalysis, Theory, Politics. Edinburgh: Edinburgh University Press.

Stavrakakis, Y. (2008) "Peripheral Vision: Subjectivity and the Organized Other: Between Symbolic Authority and Fantasmatic Enjoyment," Organization Studies Vol. 29 No. 7: 10371059.

Thoburn, N. (2003) Deleure, Marx, and Politics. London: Routledge.

Vanheule, S. and P. Verhaeghe (2004) "Powerlessness and Impossibility in Special Education: a Qualitative Study on Professional Burnout from a Lacanian Perspective," Human Relations 57(4): 497-519.

Vidaillet, B. (2007) "Lacanian theory's contribution to the study of workplace envy," Human Relations 60(11): 1669-1700.

Žižek, Slavoj (1993) "Why are the NSK and Laibach Not Fascists?" M'ARS Volume 3/4. Available at www.nskstate.com. Ljubljana: Moderna Galerija.

Zukin, S. (1989) Loft Living: Culture and Capital in Urban Change. New Brunswick, NJ: Rutgers University Press.

${ }^{i}$ For a good analysis of fascist aesthetics in relation to the avant-garde, see Hewitt (1993).

ii For more on Laibach and NSK's work in relation to this history and development of the avant-garde, see Dubravka and Djuric (2003), IRWIN (2006), and Badovinac (1999).

iii For interesting engagement with Žižek's work and Žižek-ian themes within organization studies, see De Cock Böhm (2005; 2007), Contu (2008), and Fleming and Spicer (2007).

iv One can see a parallel between the development of state rock in Yugoslavia (bands such as O! Kult and Panktri) and developments in the British post-punk scene, such as Public Image Limited claiming to be a communications and production company, or artists moving towards an adoption and overidentification with yuppie aspirations as technique of critiquing them. A number of artists, particularly Joy Division, Human League, and Magazine, drew from state socialist and totalitarian imagery their work, employing a tactic creating ambivalent effects, although perhaps nowhere nearly as disconcerting at Laibach and the NSK's work (Reynolds, 2005).

$\checkmark$ There is a wide-ranging field of literature on politics and practices of identification, identity, and the politics of organization. For a good overview see Pullen and Linstead (2005). For an exploration of the politics of disidentities, see Harney and Nyathi (2007).

vi For more on the development and use of Lacan within organization studies, see Gilles (2002; 2003), Harding (2007), Vanheule and Verhaeghe (2004), Roberts (2005), and Vidaillet (2007).

vii For more information on BAVO, see http://www.bavo.biz.

viii BAVO takes up and expand the conception of overidentification from how it was developed by the NSK and Laibach. In their formulation it becomes a more expansive notion, one that that aims to be useful outside of the particular context from where it was developed. BAVO summarize the most salient features of a strategy of overidentification as being based on these elements:

1. its effectiveness is based on sabotaging dialectics of alarm and reassurance, drawing out the extreme and obscene subtext of a social system, and eliminating the subjects reflex to make excuses for the current order to inventing new ways to manage it better

2. quickly shifts between different positions, overstating, mocking critique, and producing internal contradictions and points of tension that cannot hold together

3. sabotages easy interpretations of unproblematic identification either with or against the intervention, making it difficult to be recuperated in any direction

4. aimed precisely against the reflect to do the right thing

5. creates a suffocating closure within a system of meaning or relations, preventing escapes from the immanent laws and relations of that system (2007a: 32-37) 